ARGONNE NATIONAL LABORATORY

9700 South Cass Avenue

Argonne, Illinois 60439

TRITIUM RETENTION IN

EBR-II-IRRADLA TED BORON CARBIDE

by

C. C. Miles, S. Wexler,*

and E. R. Ebersole

Argonne-West Division

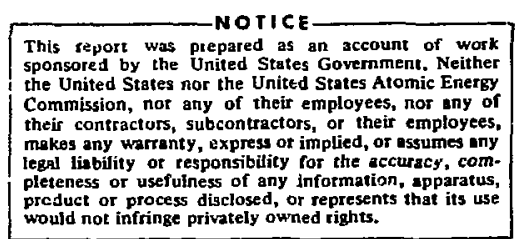

June 1974

*Chemistry Division

DISTRIBUTION OF THIS DOCUMENT IS UNLIMITED 
TABLE OF CONTENTS

$\underline{\text { Page }}$

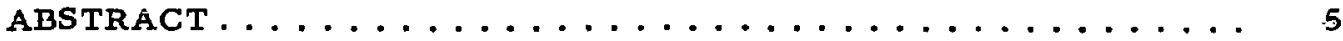

1. INTRODUCTION. ......................... 5

II. EXPERIMENTAL PROCEDURES AND RESULTS . . . . . . . . . 6

A. Irradiation of High-worth Control Rod. . . . . . . . . 6

B. Comparison of Measured and Calculated Tritium Concentrations in Boron Carbide................... 8

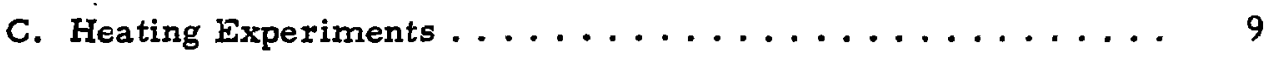

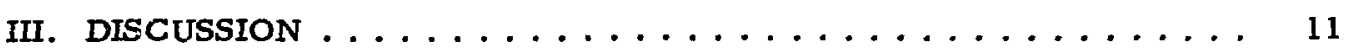

A. Production and Retention of ${ }^{3} \mathrm{H}$ in $\mathrm{B}_{4} \mathrm{C} \ldots \ldots \ldots \ldots$

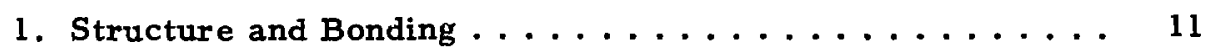

2. Nuclear Processes in $\mathrm{B}_{4} \mathrm{C} \ldots \ldots \ldots \ldots \ldots \ldots \ldots \ldots . \ldots \ldots$

3. The Mechanism of Slowing Down of Tritium Recoils . . . . 12

4. Postrapping Effects in $\mathrm{B}_{4} \mathrm{C}$ during Irradiation. . . . . . 13

B. Interpretation of ${ }^{3} \mathrm{H}$ Release Experiments ........... 14

APPENDIX: Analytical Method. .................. 16

REFERENCES ........................ 20 


\section{LIST OF FIGURES}

No.

1. Diagram of High -worth Control Rod, Showing Position of $B_{4}$ C Pellets. ....................... 7

2. Measured ${ }^{3} \mathrm{H}$ in Irradiated $\mathrm{B}_{4} \mathrm{C}$, Compared with Calculated Production of ${ }^{3} \mathrm{H}$, as a Function of Position in Control Rod. . . . . . . 8

3. Effect of Oxygen on ${ }^{3} \mathrm{H}$ Loss from $\mathrm{B}_{4} \mathrm{C}$ at $900^{\circ} \mathrm{C} \ldots \ldots \ldots \ldots$

4. Effect of Heating on ${ }^{3} \mathrm{H}$ Loss from $\mathrm{B}_{4} \mathrm{C}$ in Pure Argon. . . . . . . . 10

5. Rhombohedral Structure of Boron Carbide . . . . . . . . . . . 11

6. Diagram of Apparatus for Determination of Total Tritium Content of Boron Carbide . . . . . . . . . . . . . . . 


\title{
TRITIUM RETENTION IN \\ EBR-II-IRRADIATED BORON CARBIDE
}

by

C. C. Miles, S. Wexler, and E. R. Ebersole

\begin{abstract}
The retention and loss of tritium from EBR-II-irradiated boron carbide were investigated. The tritium content of the irradiated samples, analyzed by chemical dissolution followed by liquid-scintillation counting, showed that essentially all the tritium produced by the nuclear processes is retained by the boron carbide. Rates of tritium evolution after ir radiation were measured by heating samples in a carrier-gas stream and collecting the evolved tritium; rates of evolution were obtained as a function of temperature of the $\mathrm{B}_{4} \mathrm{C}$ during the heat treatment, the time of heating, and the atmosphere surrounding the sample. The repults reveal that tritium is substantially retained in $\mathrm{B}_{4} \mathrm{C}$ at temperatures higher than those expe rienced by EBR-II high-worth control rods. However, considerable loss of tritium occurs at temperatures above $700^{\circ} \mathrm{C}$. A theoretical model, based on the crystal structure of $\mathrm{B}_{4} \mathrm{C}$, the properties of the tritium-producing nuclear reactions, the mechanism of recoil slowing down and trapping, and posttriapping phenomena, is presented; the model qualitatively accounts for the observed retention and loss of tritium.
\end{abstract}

\section{INTRODUCTION}

The ref ractory and neutron-absorbing properties of boron carbide would appear to make it an ideal material to be used in the control rods of high-temperature liquid-metal fast breeder reactors (LMFBR's). Because of these favorable characteristics, high-density $B_{4} C$ pellets in high-worth control rods have been tested in EBR-II, and their utilization in the Fast Flux Test Facility (FFTF) is planned. However, a potentially se rious difficulty with $B_{4} C$ is the production of tritium from nuclear reactions, tritium that may be lost to the sorium coolant and eventually released to the atmosphere. Estimates made to date of the tritium inventory of the primary sodium coolant of fast reactors have assumed $100 \%$ loss of the tritium produced in $\mathrm{B}_{4} \mathrm{C}$ to the coolant, analogous to the loss of ternary-fission tritium from the fuel to the coolant. Certainly, if tritium is released from the $\mathrm{B}_{4} \mathrm{C}$ matrix at operating temperatures, it will diffuse rapidly through the stainless steel cladding to the sodium coolant. 
Tritium is formed in boron carbide by neutron reactions with both isotopes of boron,

$$
\begin{aligned}
& { }^{10} \mathrm{~B}+{ }^{1} \mathrm{n} \rightarrow{ }^{3} \mathrm{H}+2^{4} \mathrm{He}+\mathrm{Q}_{1} ; \quad Q_{1}=+0.23 \mathrm{MeV} \text {; } \\
& { }^{11} \mathrm{~B}+{ }^{1} \mathrm{n} \rightarrow{ }^{3} \mathrm{H}+{ }^{9} \mathrm{Be}+\boldsymbol{Q}_{2} ; \quad \boldsymbol{Q}_{2}=-9.55 \mathrm{MeV} .
\end{aligned}
$$

The high threshold value for Reaction 2 would preciude the reaction with ${ }^{11} B$ from contributing significantly to the production of tritium in a reactor. However, calculations show that the amount of tritium produced from ${ }^{10} B$ may equal or exceed that from ternary fission of the fuel in reactors controlled solely with high-worth control rods iHWCR's) of $\mathrm{B}_{4} \mathrm{C}$, depending on the bank-position of the rods.

Lithium is produced in the $\mathrm{B}_{4} \mathrm{C}$ from ${ }^{10} \mathrm{~B}$ according to the reaction

$$
{ }^{10} \mathrm{~B}+{ }^{1} \mathrm{n} \rightarrow{ }^{7} \mathrm{Li}+{ }^{4} \mathrm{He}+Q_{3} ; \quad Q_{3}=+2.79 \mathrm{MeV}
$$

which accounts for the major ${ }^{10} \mathrm{~B}$ burnup. About 720 atoms of ${ }^{7} \mathrm{Li}$ are produced for each atom of ${ }^{3} \mathrm{H}$; this, as discussed later, is important to the retention of ${ }^{3} \mathrm{H}$ in $\mathrm{B}_{4} \mathrm{C}$ at temperatures below $700^{\circ} \mathrm{C}$.

To determine the extent of tritium retention in the $\mathrm{B}_{4} \mathrm{C}$ irradiated in an EBR-II HWCR, samples from the $B_{4} C$ pellets were dissolved chemically and the released tritium conve rted to tritiated water, which was measu red by liquid-scintillation counting techniques. The measured values were compared to the calculated ${ }^{3} \mathrm{H}$ production.

Because of the importance of tritium loss from boron carbide cont rol rods, we also investigated the evolution of tritium from heated pieces of $\mathrm{B}_{4} \mathrm{C}$ weighing 100-200 $\mathrm{mg}$, which had been part of a 14-in. section of natural boron carbide used as a fuel follower in rod HWCR-L-4009S of EBR-II. The control rod is shown in Fig. 1. Rates of tritium evolution we re studied as a function of the temperature of the sample in the heat treatment, the time of heating, and the atmosphere surrounding the pieces. In the heat-treatment experiments, the temperature and the composition of the carrier gas flowing past the samples were carefully controlled, while the evclved tritium was collected in increments as tritiated water for the activity measurements. A theoretical model, based on the crystal structure of the boron carbide, the characteristics of the nuclear reactions, recoil slowing down and trapping, and posttrapping phenomena, has keen developed to account qualitatively for the experimental results.

\section{EXPERIMENTAL PROCEDURES AND RESULTS}

A. Irradiation of High-worth Control Rod

The boron carbide samples used in the present study were removed from a 14-in. section of natural $B_{4} C$ in a high-worth control rod (HWCR-L-4009S) 


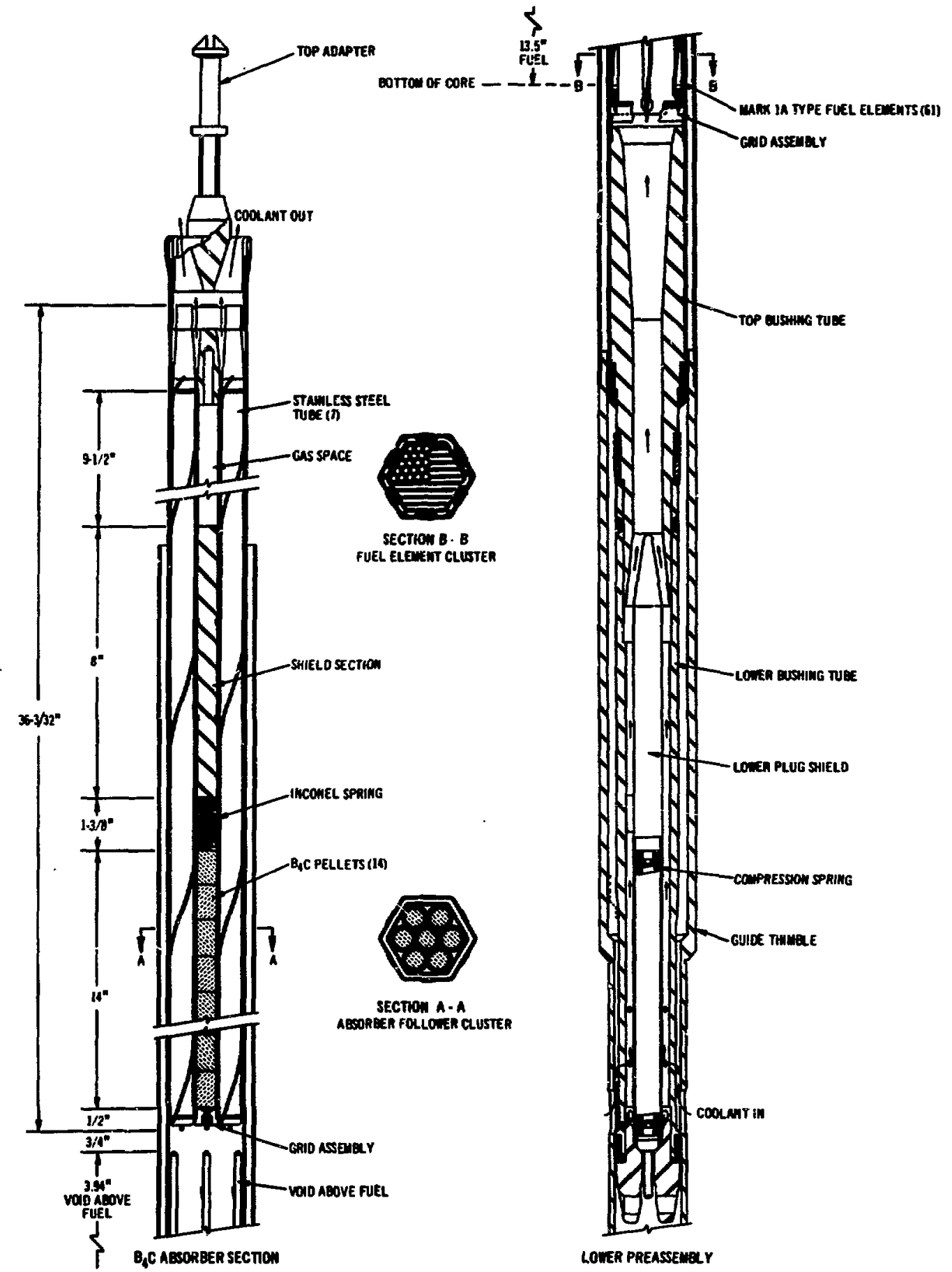

Fig. 1. Diagtam of High-worth Control Rod, Showing Position of $B_{4} C$ Pellets. ANL Neg. No. Q5366. 
(Fig. 1), which had been removed from EBR-II on March 27, 1972, after $6804 \mathrm{MWd}$ of radiation. The hardware and $\mathrm{B}_{4} \mathrm{C}$ have been examined for radiation effects. ${ }^{1}$

The in-reactor operating temperatures of the $\mathrm{B}_{4} \mathrm{C}$ portion of the HWCR were calculated to be $576^{\circ} \mathrm{C}\left(1070^{\circ} \mathrm{F}\right)$ for the pellet surface and $604^{\circ} \mathrm{C}\left(1120^{\circ} \mathrm{F}\right)$ for the pellet centerline in the region nearest the core center. In the region farthest from the core center, the pellet surface temperature was $547^{\circ} \mathrm{C}$ $\left(1017^{\circ} \mathrm{F}\right)$ and the centerline temperature was $552^{\circ} \mathrm{C}\left(1027^{\circ} \mathrm{F}\right)$.

\section{B. Comparison of Measured and Calculated Tritium Concentrations in Boron Carbide}

With the method described in the appendix, several samples of $\mathrm{B}_{4} \mathrm{C}$ from capsule $O, H W C R-L-4009 S$, were analyzed for tritium content. Briefly, samples of $\mathrm{B}_{4} \mathrm{C}$ weighing $100-200 \mathrm{mg}$ were fused in $\mathrm{NaOH}$ at $700^{\circ} \mathrm{C}$ in a silver crucible. The released tritium was converted to water by oxidation over $\mathrm{CuO}$, collected, and counted by a liquid-scintillation technique. Figure 2 compares the measured values for tritium retained in the $B_{4} C$, expressed as the number of tritium atoms per ${ }^{10} \mathrm{~B}$ atom, to the calculated tritium production values. The calculated tritium production values are from Sehgal and Rempert, ANL (solid line), ${ }^{2}$ and Lippincott, HEDL (th ree points indicated by $X^{\prime} s$ ). ${ }^{3}$ The measured values represent multiple analyses of the same pellet, all of which were within $\pm 5 \%$ of the average value. The measured tritium retained in the $\mathrm{B}_{4} \mathrm{C}$ is seen to be approximately equal to or greater than the calculated production. This indicates that probably very little of the tritium produced in the $\mathrm{B}_{4} \mathrm{C}$ is lost at EBR-II operating temperatures $\left(550-600^{\circ} \mathrm{C}\right)$. Uncertainties in the neutron fluxes and in the effective cross section for tritium production

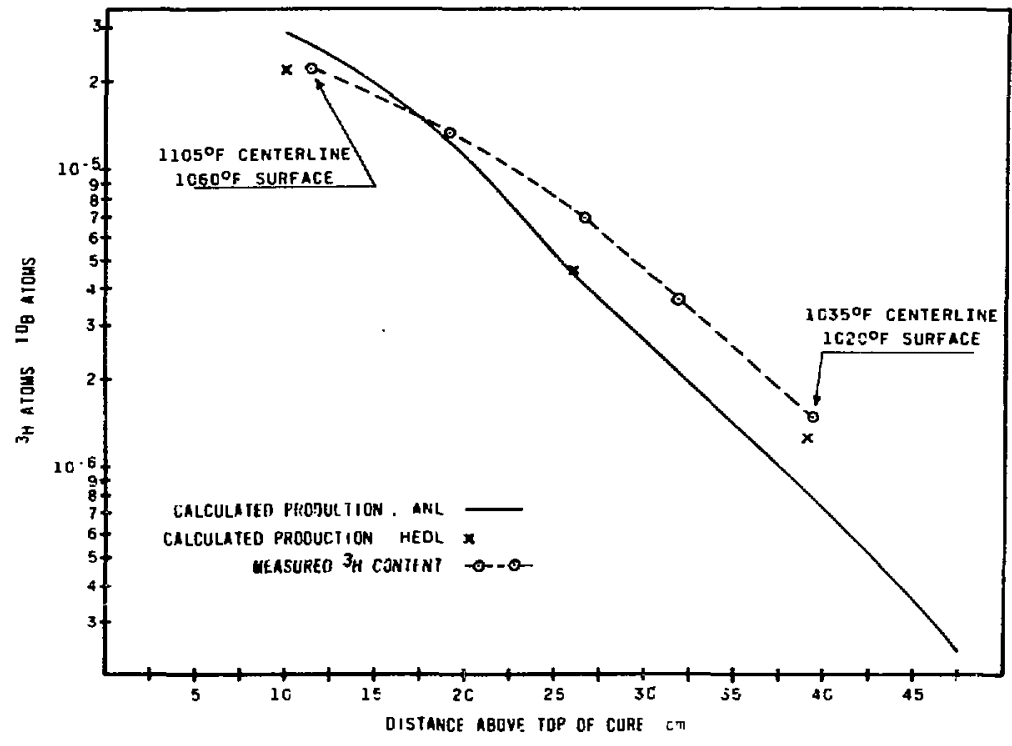

Fig. 2. Measured ${ }^{3} \mathrm{H}$ in Irradiated $\mathrm{B}_{4} \mathrm{C}$, Compared with Calculated Production of ${ }^{3} \mathrm{H}$, as a Function of Position in Control Rod 
probably account for the differences between calculated and measured values. Consistent with observations on other nuclear reactions, the disagreement becomes greater as the distance from the reactor core center increases.

\section{Heating Experiments}

Since the above results establish that virtually all the tritium is retained in the $\mathrm{B}_{4} \mathrm{C}$ at EBR-II operating conditions, the important remaining questions are how the tritium is bonded in the $\mathrm{B}_{4} \mathrm{C}$ and how firmly it is held. In the first experiments, $\mathrm{B}_{4} \mathrm{C}$ was heated at various temperatures in air and in crgon containing different concentrations of oxygen. Samples of $\mathrm{B}_{4} \mathrm{C}$ weighing 100-200 mg were heated in a flowing stream of gas, which was then passed over $\mathrm{CuO}$ to oxidize liberated ${ }^{3} \mathrm{H}$ to ${ }^{3} \mathrm{H}_{2} \mathrm{O}$. The ${ }^{3} \mathrm{H}_{2} \mathrm{O}$ was passed into cold water, which was sampled at intervals for scintillation counting. The fraction of ${ }^{3} \mathrm{H}$ removed from the sample of $\mathrm{B}_{4} \mathrm{C}$ was plotted against heating time in hours. The fraction lost was computed on the basis of the total found in the pellet by chemical analysis.

It became immediately clear that oxygen ininibits the loss of ${ }^{3} \mathrm{H}$ from $\mathrm{B}_{4} \mathrm{C}$ by forming a glassy coating of $\mathrm{B}_{2} \mathrm{O}_{3}$ on the sample surface in the temperature range above $700^{\circ} \mathrm{C}$. The inhibiting effect is illustrated in the plots of Fig. 3. At $900^{\circ} \mathrm{C}$, more than $90 \%$ of the ${ }^{3} \mathrm{H}$ is lost from a sample heated $70 \mathrm{hr}$ in pure argon, but when heated in air, less than $25 \%$ is $\mathrm{k}$ it in the same time. Because of this inhibiting effect, in subsequent experiments argon was first carefully purified by passing it over magnesium perchlorate to remcve wate $r$ and then over zirconium at $900^{\circ} \mathrm{C}$ to remove oxygen. The residual concentrations of $\mathrm{H}_{2} \mathrm{O}$ and oxygen were probably less than $1 \mathrm{ppb}$. The purified argon was passed over the heated sample and through $\mathrm{CuO}$ to oxidize the ${ }^{3} \mathrm{H}$ to ${ }^{3} \mathrm{H}_{2} \mathrm{O}$, which was collected and counted as before. The fraction lost from the $\mathrm{B}_{4} \mathrm{C}$ at a steady-state temperature was plotted against time. The results in Fig. 4 show that $\sim 90 \%$ of the ${ }^{3} \mathrm{H}$ is lost in 20 or more hours from $\mathrm{B}_{4} \mathrm{C}$ at $900^{\circ} \mathrm{C}$, and that most of the ${ }^{3} \mathrm{H}$ is retained below $700^{\circ} \mathrm{C}$.

To check the indication that $10 \%$ of the ${ }^{3} \mathrm{H}$ was retained after $80 \mathrm{hr}$ at $900^{\circ} \mathrm{C}$, a third very careful experiment was performed. In this experiment, the sample of $\mathrm{B}_{4} \mathrm{C}$ was heated to $900^{\circ} \mathrm{C}$ in purified argon, and the liberated ${ }^{3} \mathrm{H}$ was collected in water contained in a gas-wash vessel with a water-vapor trap attached to the outlet. To avoid loss, the collecting water was deliberately not sampled at intervals as before. After a steady-state heating period of $80 \mathrm{hr}$ at $900^{\circ} \mathrm{C}$, the water in the trap was combined with that in the gas-wash vesiel. The tritiated water was then diluted to volume and counted. The heated specimen was then dissolved cliemically, and the ${ }^{3} \mathrm{H}$ remaining in it was determined. Based upon the measured ${ }^{3} \mathrm{H}$ concentration originally in the $\mathrm{B}_{4} \mathrm{C}, \mathrm{a}$ material balance showed that the fraction lost on heating was 1.06 ; i.e., within limits of error, all the ${ }^{3} \mathrm{H}$ was released. The fraction left in the heated sample was 0.001 , or again within the limits of error, substantially all the ${ }^{3} \mathrm{H}$ was released. These results demonstrate conclusively that the reason the plot of Fig. 4 does not show complete loss of ${ }^{3} \mathrm{H}$ at $900^{\circ} \mathrm{C}$ is that some of the tritium was lost in the trapping frocess, in which no attempt had been made to prevent evaporation losses. 


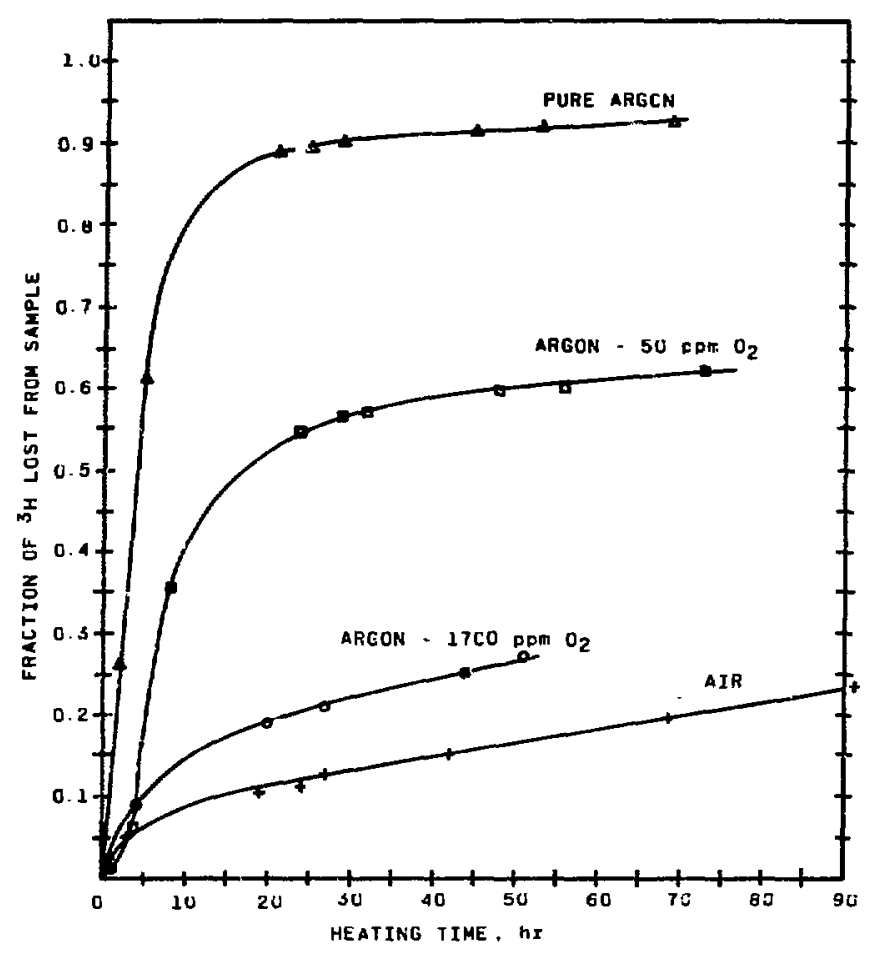

Fig. 3

Effect of Oxygen on ${ }^{3} \mathrm{H}$ Loss from $\mathrm{B}_{4} \mathrm{C}$ at $900^{\circ} \mathrm{C}$

Fig. 4

Effect of Heating on ${ }^{3} \mathrm{H}$ Loss from $\mathrm{B}_{4} \mathrm{C}$ in Pure Argon

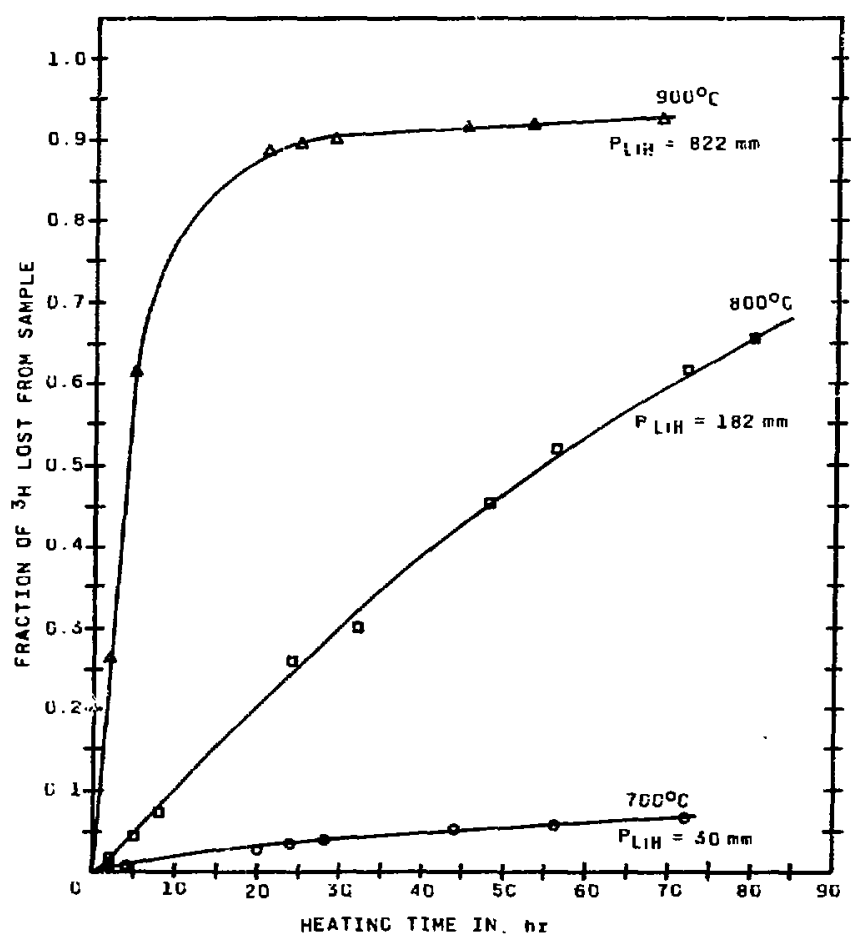




\section{DISCUSSIOIN}

A. Production and Retention of ${ }^{3} \mathrm{H}$ in $\mathrm{B}_{4} \mathrm{C}$

The experimental studiea of tritium retention by high-density boron carbide described in this report indicate that tritium is 10 st from pileirradiated material above a temperature of $\sim 650^{\circ} \mathrm{C}$. Since tritium is released from heated $\mathrm{B}_{4} \mathrm{C}$, it is of importance to understand the mechanism of its production, retention, and loss from the boron carbide lattice. This involved consideration of four determining aspects of the problem:

(1) The crystal structure of boron carbide and the nature of the chemical bonding in this compound.

(2) The characteristics of the nuclear reaction that produces tritium (e.g., the energy and state of the tritium recoil) and of other nuclear reactions whose products or effects influence the behavior of the tritium.

(3) The slowing down of tritium recoils and the properties of the available trapping sites.

(4) Posttrapping phenomena: diffusion, effects of crystallite impurities and defects, the effects of oxygen and $\mathrm{H}_{2} \mathrm{O}$ in the atmosphere surrounding the $\mathrm{B}_{4} \mathrm{C}$, and possible phase changes.

1. Structure and Bonding

Boron carbide possesses a rhombohedral structure (as shown in Fig. 5), whose structural units contain 12 boron atoms, arranged at the vertices of a regular icosahedron, and a linear chain of three carbons. ${ }^{4}$ Thus its chemical formula is actually $B_{12} C_{3}$, rather than the simplified $B_{4} C$ usually written. Each boron atom has five equidistant boron atoms as nearest neighbors in its own icosahedron, and may also be bonded to an end carbon atom of the linear chain or to a boron atom of an adjacent icosahedral group. The end carbon atoms are each bound to boron atoms of three adjacent icosahedrons, while the middle carbon atom is attached only to the two end carbons. The bond

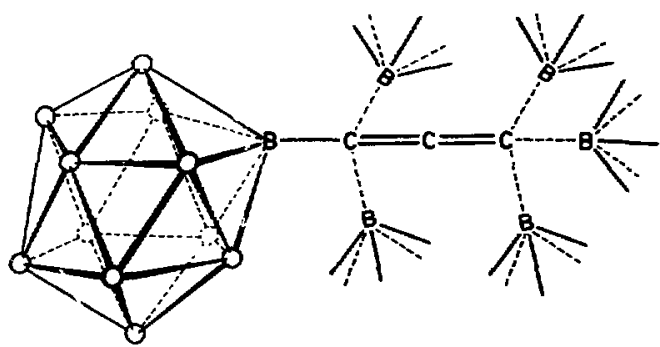

Fig, 5. Rhombohedral Structure of Boron Carbide. ANL Neg. No. 103-R5815. lengths are $B-B, 1.74-1.80 \AA ; B-C$, $1.64 \AA ; C-C, 1.39-1.45 \AA$. The boron carbide lattice therefore has the appearance of "geodesic domes" tied together at their vertices or through linear chains of three carbon atoms. The bonds between the boron atoms are obviously not electron-pair (covalent), since each atom has only three valency electrons but forms six bonds. Conse"quently, the bonding is more closely metallic. The attachment of three electron-deficient boron atoms to each 
end carbon atom makes it likely that the middle carbon atom is either divalent or connected by double bonds to the other carbons. The three-dimensional structures of boron atoms form very stable lattices, through which valence electrons and, at high enougin temperatures, metallic impurity atoms migrate with ease.

2. Nuclear Processes in $B_{4} C$

Nuclear processes involved in the neutron irradiation of $\mathrm{B}_{4} \mathrm{C}$ were mentioned in Sec. I above. The two reactions of interest to us in this discussion are Reactions 3 and 1 :

$$
\begin{aligned}
& { }^{10} \mathrm{~B}+{ }^{1} \mathrm{n} \rightarrow{ }^{7} \mathrm{Li}+{ }^{4} \mathrm{He} \\
& { }^{10} \mathrm{~B}+{ }^{1} \mathrm{n} \rightarrow{ }^{3} \mathrm{H}+2^{4} \mathrm{He} .
\end{aligned}
$$

After exposure of $B_{4} C$ to the neutron flux of $E B R-I I$, the ratios of products resulting from reactions are app roximately ${ }^{7} \mathrm{Li}:{ }^{4} \mathrm{He}:{ }^{3} \mathrm{H}=720: 720: 1$. For the $\mathrm{B}_{4} \mathrm{C}$ studied here, the ${ }^{10} \mathrm{~B}$ "burnup" was 1.5 at. $\%$, which corresponds to 0.24 at. $\%{ }^{7} \mathrm{Li}$. A determination of lithium in a sample of $\mathrm{B}_{4} \mathrm{C}$ gave $-1700 \mathrm{ppm}$ by weight. The calculated value was $1620 \mathrm{ppm}$, within $5 \%$ of that found. Data collected by Patriarca indicate that the lithium occupies interstitial sites randomly distributed within the $\mathrm{B}_{4} \mathrm{C}$ lattice, with no evidence of a lithium-rich phase. ${ }^{5}$

Taking into account the isotopic abundance of ${ }^{10} \mathrm{~B}$, we ealculate that one boron atom in about 339 , or one icosahedron in 28 , has been affected during the neutron irradiation. In addition, the structure of $B_{4} C$ will have been damaged by fast neutrons, high-energy gamma rays, and $X$ rays, and by energy conversion during the slowing down of the energetic recoils from Reactions 1 and 3.

The kinetic exoergicity, $Q$, of the tritium-producing Reaction 1 is $232 \mathrm{keV}$, so that the recoil energy of the ${ }^{3} \mathrm{H}$ is $169 \mathrm{keV}$.

\section{The Mechanism of Slowing Down of Tritium Recoils}

Having experienced a recoil of $169 \mathrm{keV}$, the triton will lose its kinetic energy by several collisions with boron (mainly) and carbon atorns. The principal mode of energy loss at lower kinetic energies is usually nuclear stopping; i.e., by kinetic-energy transfer in collisions of atoms, but at higher energies, electronic stopping contributes greatly. ${ }^{6}$ The latter mechanism may indeed be dominant for tritium ions because of the complete lack of shell electrons in this ion. ${ }^{7-9}$ In an electron-deficient crystalline lattice such as $B_{4} C$, furthermore, the tritiun recoil may very well exist as a positive ion over its entire slowing-down path. However, the path length and projected range, i.e., the projection of the actual path length along the initial direction of the recoil, may each be estimated to be about $10^{-4} \mathrm{~cm}^{9}$ consequently, the tritium recoil comes to rest at a relatively great distance from the place of its birth. The time of slowing down is extremely short--less than $10^{-12} \mathrm{sec}$. 
Of far greater importance in determining ${ }^{3} \mathrm{H}$ retention in bo ron carbide than the mechanisms of energy loss are the trapping and bonding sites available to the energy-degraded recoil ion. The undisturbed $B_{4} C$ lattice offers two aites: (a) interstitial space within each icosahedron, and (b) chemical bonding to the middle atom of the linear three-carbon-atom chain. Becauge of the electron-deficient nature of the $B_{12}$ structural unit, the recoil will probably come to rest, in most cases, as a ${ }^{3} \mathrm{H}^{+}$ion within it, but the high mobility of electrons in the metallic bonds of the $B_{12}$ lattice should favor partial neutralization of the tritons. However, the surplus of electronic charge near the middle of the carbon chain would be expected to promote formation of a strong covalent $C{ }^{3} \mathrm{H}$ bond at that position. In addition to these two "normal" sites, the tritium may be trapped by the far more numerous recoil lithium atoms. The latter have also come to rest within the "geodesic" domes, but should be present as $\mathrm{Li}^{+}$ions there; consequently, the tritium trapping by lithium may not occur within the domes, but at grain boundaries to which the ions may migrate rapidly at the ambient temperature of the reactor, and where they may be neutralized by surface electrons. X-ray diffraction, scanningelectron microscopy, and nuclear-magnetic-resonance studies ${ }^{5}$ on irradiated $\mathrm{B}_{4} \mathrm{C}$ indicate, however, that the lithium occupies interstitial sites randomly in the lattice. There was no evidence for a second, lithium-rich phase. From these results, it was concluded that the lithium is present as ions in various sites with different quad rupole coupling constants and asymmetry parameters, even when the neutron irradiation occurred at $730^{\circ} \mathrm{C} .{ }^{5}$ Nevertheless, the absence of a lithium-rich phase does not preclude the presence of numerous lithium atoms dispersed along grain boundaries. Other trapping sites will be at imperfections and lattice vacancies caused by fast-neutron interactions and the nuclear reactions themselves.

\section{Posttrapping Effects in $\mathrm{B}_{4} \mathrm{C}$ during Irradiation}

Diffusion of the thermalized recoil species during the period of irradiation in EBR-II, and trapping by lithium atoms and possibly by carbon atoms in the boron carbide, exert the dominant influences on the extent of retention of tritium in reactor-irradiated $B_{4} C$.

Although diffusion rates have not been determined for ${ }^{3} \mathrm{H}^{+}$and $\mathrm{Li}^{+}$ in $B_{4} C$, measurements ${ }^{10,11}$ on metal borides, metal carbohydrides, and silicon semiconductors suggest that, at sufficiently high temperatures, the tritium $\left(\right.$ as ${ }^{3} \mathrm{H}^{+}$) and lithium (as $\mathrm{Li}^{+}$) as well as the $\mathrm{He}^{+}$produced in the nuclear reactions 1-3 diffuse rapidly through the lattice. The diffusion rates of these ionic species may be as high as $10^{-6} \mathrm{~cm}^{2} \mathrm{sec}^{-1}$ or even higher at the reactor temperature; consequently, mean diffusion distances should be of the order of $1 \mathrm{~cm}$ after $100 \mathrm{hr}$ of irradiation. $(\overline{\mathrm{S}}=\sqrt{\mathrm{dt}}$, where $\overline{\mathrm{S}}=$ mean diffusion distance, $d=$ diffusion rate, and $t=$ time of heating.) This distance is greater than the radius of an irradiated $\mathrm{B}_{4} \mathrm{C}$ peilet. Thus, the calculation indicates a substantial loss of tritium from irradiated $\mathrm{B}_{4} \mathrm{C}$. Since no tritium is released from the pellets during reactor irradiation, the tritium must be chemically trapped. Thermal annealing such as occurs during the reactor irradiation must cause the $\mathrm{Li}^{+}$and ${ }^{3} \mathrm{H}^{+}$ions to collect at $\mathrm{grain}$ boundaries and surfaces, where they are neutralized by surface electrons and then combine 
to form lithium tritide. An alternative destination of the energy-degraded tritium ions could be the central atom of the carbon chain. It is of interest that $X$ - ray analysis ${ }^{5}$ shows that the rhombohedral angle, the unit-cell length, and the volume of reactor-irradiated $\mathrm{B}_{4} \mathrm{C}$ all change drastically between 700 and $1000^{\circ} \mathrm{C}$, reverting above the higher temperature to their respective values characteristic of unirradiated material. Nevertheless, differential thermal analyses gave no evidence for a phase change in this temperature region. ${ }^{12}$ These observations are consistent with the diffusion of the three products of the nuclear reactions out of the lattice to grain boundaries and surfaces.

\section{B. Interpretation of ${ }^{3} \mathrm{H}$ Release Experiments}

The fraction of tritium released from compacted boron carbide that had been irradiated in EBR-II is seen from the experimental results to rise rapidly with time, and then either become constant or rise slowly. Both the initial rate of increase and the ultimate fraction of tritium lost are strongly dependent on the temperature of the $\mathrm{B}_{4} \mathrm{C}$, its state of aggregation, and the presence of oxygen in the atmosphere surrounding the heated sample. Below $650^{\circ} \mathrm{C}$, no tritium is released, as shown by comparison of the tritium content of a sample with that expected from calculations based on neutron flux, the known reaction cross sections, the number of ${ }^{10} \mathrm{~B}$ nuclei, and the length of time of irradiation in EBR-II. If the $B_{4} C$ is heated to $900^{\circ} \mathrm{C}$, and no special purification of the argon entrainment gas is undertaken to remove traces of oxygen ( $\sim 50 \mathrm{ppm})$ and $\mathrm{H}_{2} \mathrm{O}(\sim 200 \mathrm{ppm})$, about $60 \%$ of the tritium is released after $70 \mathrm{hr}$ (see Fig. 3). When special effort is made to remove oxygen and $\mathrm{H}_{2} \mathrm{O}$ from the carrier argon, and precautions are taken to minimize evaporation losses, the fraction removed from pieces of the pellet at $900^{\circ} \mathrm{C}$ is increased $-100 \%$. The presence of very small concentrations of added oxygen $(\sim 0.17 \%)$ in the atmosphere surrounding the heated sample strongly reduces the amount of tritium released at $900^{\circ} \mathrm{C}$. Heating the $\mathrm{B}_{4} \mathrm{C}$ in air also causes a marked reduction in loss at $900^{\circ} \mathrm{C}$, and is accompanied by massive oxidation of the sample to form a heavy glassy coating of $\mathrm{B}_{2} \mathrm{O}_{3}$.

The experimental results the refore are consistent with a mechanism in which the tritium recoils are thermalized and come to rest as ions within the icosahedral arrays. At the temperature of the pellets in the reactor, the ions diffuse rapidly through the lattice to grain boundaries and surfaces, where they are neutralized and trapped by the much more numerous lithium atoms from the ${ }^{10} \mathrm{~B}(\mathrm{n}, \alpha)^{7} \mathrm{Li}$ nuclear reaction, which have also diffused rapidly to grain boundaries and surfaces and have then become neutralized by surface electrons. The formation of stable $\mathrm{Li}^{3} \mathrm{H}$ and $\mathrm{C}^{3} \mathrm{H}$ bonds (the bond energies are 2.4 and $3.5 \mathrm{eV}$, respectively) at the ambient temperature of the reactor is responsible for the complete retention of tritium in boron carbide control rods.

The loss of tritium above $650^{\circ} \mathrm{C}$ in the thermal gas-release experiments reported here is probably a direct result of the decomposition of $\mathrm{Li}^{3} \mathrm{H}$. This may be concluded from the properties of its isotopic analog, LiH. Lithium hydride first begins to decompose in vacuum at $450^{\circ} \mathrm{C}$, and the dissociation 
pressure (as $\mathrm{H}_{2}$ ) increases rapidly in the $800-950^{\circ} \mathrm{C}$ range. ${ }^{13}$ Our results suggest, furthermore, that the fraction of tritium atoms that may be trapped by chemical combination with the middle carbon atoms of the three-member side chains appear to be very slight, despite the stronger bond expected, since from the ${ }^{3} \mathrm{H}$ release experiments, they appear to comprise almost none of the recoils. 


\section{APPENDIX}

Analytical Method

1. Introduction

A simple and rapid method was required to determine the amount of ${ }^{3} \mathrm{H}$ in $\mathrm{B}_{4} \mathrm{C}$. A chemical reaction that would completely consume the $\mathrm{B}_{4} \mathrm{C}$ was considered as the best approach, since this would give the proper conditions to release all the ${ }^{3} \mathrm{H}$ either as the element, as water, or as some other volatile compound.

Attempts to burn the $\mathrm{B}_{4} \mathrm{C}$ in pure oxygen were unsuccessful, because a glaze of $\mathrm{B}_{2} \mathrm{O}_{3}$ formed on the surface and slowed further reaction to an imperceptible rate. Fusion of $\mathrm{B}_{4} \mathrm{C}$ with $\mathrm{Na}_{2} \mathrm{O}_{2}$ gave an explosively reactive mixture. Also, the melt was very difficult to contain because of the high heat of reaction and the extremely corrosive properties of the $\mathrm{Na}_{2} \mathrm{O}_{2}$. The best results were obtained by the fusion technique, with $\mathrm{NaOH}$ as the flux. The reaction rate is easily controlled by temperature and proceeds smocthly, and the melt can be contained in a silver crucible.

\section{Analytical Method}

\section{a. Principle}

$\mathrm{B}_{4} \mathrm{C}$ is reacted with 20 times its weight of $\mathrm{NaOH}$ in a deep-form silver crucible held at $650-700^{\circ} \mathrm{C}$. A gas mixture of $\mathrm{He}-10 \% \mathrm{H}_{2}$ is passed over the melt to sweep out the ${ }^{3} \mathrm{H}, \mathrm{H}^{3} \mathrm{HO}$, and any other possible volatiles containing ${ }^{3} \mathrm{H}$. This gas mixture is passed over a bed of $\mathrm{CuO}$ held at $500-600^{\circ} \mathrm{C}$, where tritium or any compound of tritium is converted to tritiated water. The combustion products then pass through a water-cooled condenser, where the tritiated water condenses to a liquid and then passes into a beaker containing water cooled to $0^{\circ} \mathrm{C}$.

After the fusion is completed, the crucible is cooled to less than $100^{\circ} \mathrm{C}$. Dilute acetic acid is added to the crucible in excess to neutralize completely the unreacted $\mathrm{NaOH}$. The water and any excess acetic acid are then distilled through the $\mathrm{CuO}$ bed, the sweep gas mixture being a mechanical aid for carrying the vapor. This procedure removes the last traces of ${ }^{3} \mathrm{H}$ held in the melt and transfers it as tritiated water to the cooled beaker.

The tritiated water in the beaker is then diluted to $100 \mathrm{ml}$, and the amount of ${ }^{3} \mathrm{H}$ determined by liquid-scintillation counting.

\section{b. Apparatus}

The apparatus used in the chemical determination of total tritium in $\mathrm{B}_{4} \mathrm{C}$ is shown in Fig. 6. 


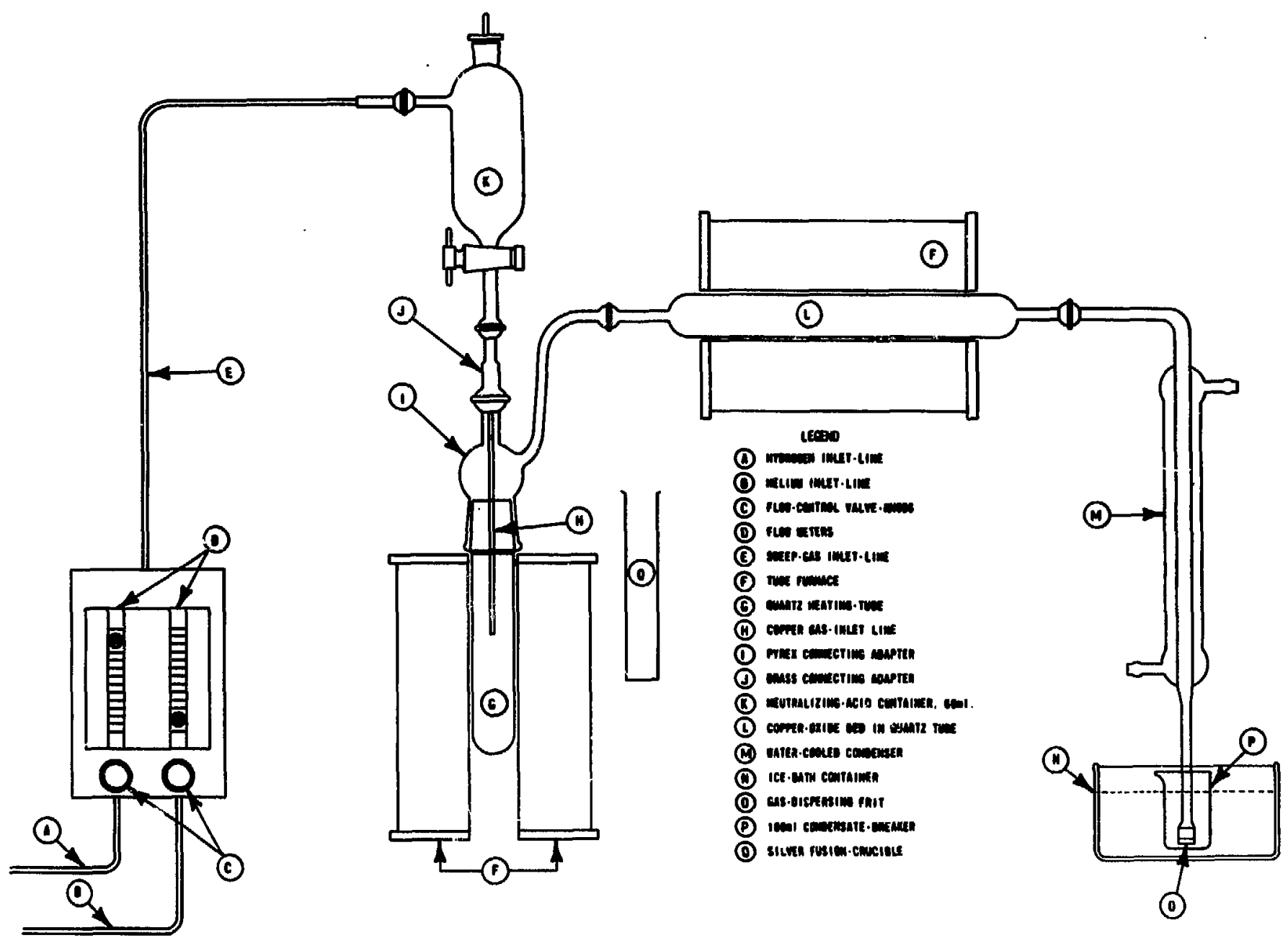

Fig. 6. Diagram of Apparatus for Determination sf Total Tritium Content of Boron Carbide. ANL Neg. No. 103-R5818. 
The hydrogen and helium inlet lines $A$ and $B$ are 1/8-in. copper tubes, which conduct the gases from standard pressure regulators fed by pressurized-gas bottles. The flow-regulating needle valves $\mathrm{C}$ and flowindicating meters $\mathrm{D}$ may be any type capable of regulating and reading helium flow from 6 to $100 \mathrm{ml} / \mathrm{min}$ and hydrogen flow from 5 to $50 \mathrm{ml} / \mathrm{min}$. The sweep-gas inlet line $E$ may be rubber or copper, but should be easily manipulated, since it is attached and removed several times during the analysis.

The neutralizing-acid container $\mathrm{K}$ is a modified $60-\mathrm{ml}$ Pyrex separatory funnel with a Teflon stopcock. The brass connecting adapter $\mathrm{J}$ is made of silver-soldered, spherical-ground brass fittings and a short piece of $1 / 8$-in. soft-copper tubing.

The Pyrex connecting adapter I is made of a female 34/45 standardtaper joint, and is wrapped with a heating tape (152 W), so that its entire outer surface can be heated above $100^{\circ} \mathrm{C}$. The heating tape is attached with a woven glass sticky tape. The adapter is insulated to prevent heat loss by a layer of the sticky tape on the outside of the heating tape. The heating tube $G$ is made of a, quartz male 34/45 standard-taper joint and a piece of standard-wall quartz tubing of matching diameter. The heating tube is heated by an electric multi unit tube furnace $F$, which was rewired to give $1200 \mathrm{~W}$ for rapid response in heating. The furnace is 10 in. long and will take a $1 \frac{1}{4}$-in. tube. The power to the furnace is delivered by a controller that senses the temperature through a 1/16-in. stainless-sheathed Chromel-Alumel thermocouple. The thermocouple is placed about midway in the side of the furnace to sense the temperature at about the point where the bottom of the silver fusion crucible is located. When desired, this high-wattage furnace is cooled with an air blast directed from the bottom.

The copper oxide bed $L$ is made of tightly packed fine copper turnings insides a quartz tube, which is $\sim 10$ in. long and 30-35 mm in outside diameter. The copper oxide is prepared by heating the copper to $600 \pm 10^{\circ} \mathrm{C}$ and passing air through it at $\sim 200 \mathrm{ml} / \mathrm{min}$ for $18-24 \mathrm{hr}$. The heater for the copper oxide bed is a 10 -in.-long, 584-W multiunit tube furnace, capable of taking a tube with 30 to $35-\mathrm{mm}$ OD. The controller for this furnace senses the temperature by a Chromel-Alumel thermocouple placed outside the tube at the midpoint of the $\mathrm{CuO}$ bed.

The condenser $M$ is an ordinary, straight-tube type of 10 to $15-\mathrm{mm}$ ID, with a narrow cooling jacket. The lower end of the condenser is fitted with a frit $O$, which bieaks up the gas stream into fine bubbles as it passas into water contained in the $100-\mathrm{ml}$ condensate-collecting beaker $P$. The beaker is cooled in an ice bath in a shallow 1 -liter crystallizing dish $\mathbf{N}$.

For the determination of tritium content of the condensate, a liquid-scintillation counter was used. The counter had an efficiency for ${ }^{3} \mathrm{H}$ alone of about $30 \%$. 


\section{c. Procedure}

Weigh a clean dry piece of $B_{1} C(0.1-0.2 \mathrm{~g})$, and transfer to the silver fusion-crucible. Add 20 times this weight of $\mathrm{NaOH}$ (reagent grade), in pellet form, to the fusion crucible. Lubricate the ground surfaces of all the inner members of each joint with Dow-Corning Vacuum Grease. Slip the silver crucible into the quartz heating tube, and assemble the apparatus as shown in Fig. 6, but without the neutralizing-acid container, attaching the gas-inlet line $\mathrm{E}$ directly to the brass connecting adapter $\mathrm{J}$.

Heat the copper oxide bed to $600 \pm 10^{\circ} \mathrm{C}$. Establish a flow rate of $90-100 \mathrm{ml} / \mathrm{min}$ for the helium and $5-15 \mathrm{ml} / \mathrm{min}$ for the hydrogen. Flace about $20 \mathrm{ml}$ of distilled or demineralized water in the $100-\mathrm{ml}$ condensate beaker. Check to be certain that bubbles through the frit are indicating flow, as this will serve as a rough leak check. After making certain that the appa ratus is leak-tight, adjust the temperature of the tube-furnace heater to $600-700^{\circ} \mathrm{C}$. Heat the silver crucible for $90 \mathrm{~min}$ at $600-700^{\circ} \mathrm{C}$; then remove the gas-inlet line. Remove the quartz heating tube with the Pyrex-glass adapter attached, and allow the assembly to cool to $<100^{\circ} \mathrm{C}$. In the meantime, cool the furnace to $<100^{\circ} \mathrm{C}$ with an airblast directed up through the heating zone. When the furnace and fusion as sembly are cooled, reassemble the equipment as shown in Fig. 6, with the neutralizing-acid container in place. Pour $25 \mathrm{ml}$ of $25 \%$ acetic acid into the acid container, and open the stopcock. Place the plug in the acid container and seat it tightly, so as to force the acetic acid into the silver fusion-crucible. Allow the gas to bubble through the solution in the silver fusion crucible for $\sim 10 \mathrm{~min}$; then raise the temperature of the furnace to $\sim 120^{\circ} \mathrm{C}$, and allow this heating rate to continue for $1 \mathrm{hr}$. After $1 \mathrm{hr}$, raise the furnace temperature to $200^{\circ} \mathrm{C}$ for $30 \mathrm{~min}$, then to $400^{\circ} \mathrm{C}$ for $30 \mathrm{~min}$. At the end of this neutralization-distillation procedure, turn off the hydrogen flow and use a heat gun to heat the inlet to the copper oxide bed to force any condensed liquid through the train. Heat the outlet also until all condensed water is well inside the condenser inlet. At this time, the volume of liquid in the condensate beaker should be about $50 \mathrm{ml}$. Detach the condenser from the outiet of the copper oxide bed. Rinse the inside of the condenser into the condensate beaker with several portions of water. Also rinse the outside of the frit and the lower end of the condenser into the condensate beaker.

Quantitatively transfer the condensate to a $100-\mathrm{ml}$ volumetric flask. Dilute to volume, and prepare the solution for counting. 


\section{REEERENCES}

1. L. C. Walters, M. T. Laug, W. E. Ruther, and H. A. Taylor, Jr., Postirradiation Examination of Higher-worth Control Rods L-4008S and L-4009S, ANL/EBR-070 (May 1973).

2. B. R. Sehgal and R. H. Rempert, ANL, private sommunication (Apr 1971).

3. E. P. Lippincott, Hanford Engineering Development Laboratory, private communication (Jan 1973).

4. A. F. Wells, Structural Chemistry, pp. 823-826, Oxford University Press, London (1962).

5. P. Patriarca, in Fuels and Materials Development Program, Quarterly Progress Report, pp. 38-58, ORNL-TM-3703 (Dec 31, 1971).

6. G. Harbottle and $\mathrm{N}$. Sutin, in Advances in Inorganic Chemistry and Radiochemiatry, H. J. Emeleus and A. G. Sharpe, eds., Vo1. 1, p. 267, Academic Press, New York (1959).

7. J. Lindhard, M. Scharff, and H. E. Schloett, Range Concepts and Beavy Ion Ranges (Notes on Atomic Collisions) II, Mat. Fys. Medd. Dan. Vitd. Selsk. 33, No. 14,1 (196j) .

8. J. W. Mayer, L. Erlksson, and J. A. Davles, Ion Implantation in SemiConductors, silicon and Germanizm, Academic Press, New York (1970).

9. L. C. Northcliffe and R. F. Schilling, Range and Stopping Power Tables for Heavy Ions, Nuclear Data Tables 8, 255 (1970).

10. H. Goretzki, E. Ganglberger, H. Nowotny, and H. Bittner, On the Problem of the Carbohydrides, Monatsh. Chem. 96, 1563 (1955).

11. B. I. Bottaks, Diffusion in Semiconductors, p. 218, Academic Press, New York (1963).

12. H. R. Hoekstra, ANL, private communication (Hay 1973).

13. E. Veleckis, E. VanDeventer, and $M$. Blander, The Lithizm-Lithizon Hydride System, J. Phys. Chem. (In press, 1974). 